\title{
DO GINÁSIO INDUSTRIAL DE PETROLINA À ESCOLA MARECHAL ANTÔNIO ALVES FILHO: VESTÍGIOS DA CULTURA ESCOLAR (1962-1971) ${ }^{1}$
}

\author{
Virgínia Pereira da Silva de Ávila \\ Universidade de Pernambuco, Campus de Petrolina \\ virginia.avila@upe.br \\ Kalline Laira Lima dos Santos \\ Universidade de Pernambuco, Campus de Petrolina \\ lairakalline@,gmail.com
}

\begin{abstract}
RESUMO
Neste texto, apresentam-se resultados da pesquisa investigativa que analisou vestígios da cultura escolar presentes na documentação do primeiro ginásio do município de Petrolina, no Sertão do São Francisco, no período entre 1962 e 1971. A pesquisa se apoiou nos textos legislativos, bem como nas fichas individuais e antropométricas, por meio dos quais buscou identificar as práticas culturais e o perfil socioeconômico e educacional dos(as) alunos(as). A delimitação temporal compreende o ano de fundação do ginásio e a mudança de nomenclatura advinda com a Lei n. 5.692/71. Com relação ao referencial teórico, privilegiou-se o diálogo entre autores (as) do campo da História e da Historiografia da Educação, mais especificamente aqueles relacionada à História Cultural. Os dados iniciais permitiram identificar o papel do antigo ginásio na difusão da cultura, das atividades esportivas e da fé nos diferentes espaços da cidade. Por fim, o trabalho aponta para um conjunto de possibilidades para investigações futuras.
\end{abstract}

Palavras-chave: Petrolina. Ginásio Industrial. Cultura escolar.

\section{FROM THE PETROLINA INDUSTRIAL GYMNASIUM TO THE MARECHAL ANTÔNIO ALVES FILHO SCHOOL: TRACES OF SCHOOL CULTURE (1962-1971)}

\begin{abstract}
In this text, we present results of the research that analyzed vestiges of the school culture present in the documentation of the first gymnasium of the municipality of Petrolina, in the Sertão do São Francisco, between 1962 and 1971. The research was based on the legislative texts, as well as on the individual and anthropometric charts, through which it sought to identify the cultural practices and the socioeconomic and educational profile of the students. The temporal delimitation includes the year of foundation of the gymnasium and the change of nomenclature with Law n. 5,692/71. Regarding the theoretical reference, the dialogue between authors of the field of History and the Historiography of Education, especially those related to Cultural History, was favored. The initial data allowed to identify the role of the old gymnasium in the diffusion of culture, sports activities and faith in the different spaces of the city. Finally, the paper points to a set of possibilities for future research.
\end{abstract}

\footnotetext{
${ }^{1} \mathrm{O}$ trabalho se insere no âmbito do projeto de pesquisa "Os arquivos escolares como fonte de pesquisa para a história da educação", desenvolvido na linha de pesquisa Estudos históricos sobre escola, cultura e memória, vinculada ao Grupo de Estudos e Pesquisas em História da Educação no Sertão do São Francisco - GEPHESF, da Universidade de Pernambuco. Conta com financiamento da Fundação de Amparo à Ciência e Tecnologia de Pernambuco (FACEPE).
} 
Keywords: Petrolina. Industrial Gymnasium. School culture.

\section{DEL GIMNASIO INDUSTRIAL DE PETROLINA A LA ESCUELA MARECHAL ANTÔNIO ALVES FILHO: VESTIGIOS DE LA CULTURA ESCOLAR (1962-1971)}

\section{RESUMEN}

En este texto, se presentan resultados de la investigación investigativa que analizó vestigios de la cultura escolar presentes en la documentación del primer gimnasio del municipio de Petrolina, en el Sertão do São Francisco, en el período entre 1962 y 1971. La investigación se apoyó en los textos legislativos, así como en las fichas individuales y antropométricas, por medio de los cuales buscó identificar las prácticas culturales y el perfil socioeconómico y educativo de los alumnos. La delimitación temporal comprende el año de fundación del gimnasio y el cambio de nomenclatura que viene con la Ley n. 5.692/71. Con respecto al referencial teórico, se privilegió el diálogo entre autores (as) del campo de la Historia y de la Historiografía de la Educación, más específicamente aquellos relacionados a la Historia Cultural. Los datos iniciales permitieron identificar el papel del antiguo gimnasio en la difusión de la cultura, de las actividades deportivas y de la fe en los diferentes espacios de la ciudad. Por último, el trabajo apunta a un conjunto de posibilidades para futuras investigaciones.

Palabras-clave: Petrolina. Gimnasio Industrial. Cultura escolar.

\section{DU GYMNASE INDUSTRIEL PETROLINA À L'ECOLE MARÉCHAL ANTÔNIO ALVES FILHO: TRACES DE LA CULTURE SCOLAIRE (1962-1971)}

\section{RÉSUMÉ}

Dans ce texte, nous présentons les résultats de la recherche qui a analysé les vestiges de la culture scolaire présents dans la documentation du premier gymnase de la municipalité de Petrolina, dans le Sertão do São Francisco, entre 1962 et 1971. La recherche a été basée sur les textes législatifs, ainsi que sur les graphiques individuels et anthropométriques, à travers lesquels elle a cherché à identifier les pratiques culturelles et le profil socio-économique et éducatif des étudiants. La délimitation temporelle comprend l'année de fondation du gymnase et le changement de nomenclature avec la loi n. 5,692/71. En ce qui concerne la référence théorique, le dialogue entre les auteurs du domaine de l'histoire et l'historiographie de l'éducation, en particulier ceux liés à l'histoire culturelle, a été favorisé. Les premières données ont permis d'identifier le rôle de l'ancien gymnase dans la diffusion de la culture, des activités sportives et de la foi dans les différents espaces de la ville. Enfin, le document pointe vers un ensemble de possibilités pour la recherche future.

Mots-clés: Petrolina. Gymnase industriel. Culture scolaire.

\section{INTRODUÇÃO}

Há uma cor que não vem nos dicionários. É essa indefinível cor que têm todos os retratos, os figurinos da última estação, a voz das velhas damas, os primeiros sapatos, certas tabuletas, certas ruazinhas laterais: - a cor do tempo... (QUINTANA, 1940, p. 97) 
Neste trabalho, apresentam-se resultados de pesquisa investigativa que analisou vestígios da cultura escolar presentes na documentação do primeiro ginásio do município de Petrolina, no Sertão do São Francisco, no período entre 1962 e 1971. A pesquisa se apoiou nos textos legislativos, bem como nas fichas individuais e antropométricas dos(as) alunos(as), considerando aspectos relativos ao sexo, idade, naturalidade, peso, altura, bem como dados concernentes às festas e às atividades culturais presente na história da escola. $\mathrm{O}$ objetivo foi identificar as práticas culturais e o perfil socioeconômico e educacional dos(as) alunos(as). A delimitação temporal compreendeu o ano de fundação do ginásio e a mudança de nomenclatura advinda com a Lei n. 5.692/71.

Em relação ao referencial teórico, privilegiou-se o diálogo com diferentes autores do campo da História e da Historiografia da Educação, especificamente aqueles relacionados à História Cultural, bem como da Arquivologia.

Quanto ao percurso da História da Educação, nos últimos anos, é notável o aumento das pesquisas nesse campo. A Nova História Cultural teve uma contribuição importante nesse avanço. Foi com essa nova possibilidade de fazer história, uma história que viabilizasse o interior e o micro, com foco nas diversas ações humanas, que possibilitou recuperar acontecimentos e histórias que estavam recobertas na poeira do tempo (BURKER, 1997).

Baseado nos percursos epistemológicos, teóricos e metodológicos da Nova História e da Nova História Cultural, esse novo modo de fazer história abriu uma dimensão de novos objetos, novas fontes e abordagens. No Brasil, por exemplo, os estudos relativos à memória educativa e aos arquivos escolares tornaram-se um campo específico de investigação na área de História da Educação (SAVIANI, 2007). Esse processo ganhou impulso a partir de 1990 com a ampliação dos temas, objetos e fontes. São os estudos culturais e sociais, a história das instituições, das práticas escolares e da cultura material que açucaram esse campo científico. O que estava recôndito emerge ao "sótão".

Com relação ao uso da cultura escolar como categoria de análise, adotou-se a perspectiva conceitual de Frago (1995). Para ele, a cultura escolar recobre as diferentes manifestações das práticas instauradas no interior das escolas, transitando de alunos a professores, de normas a teorias. Em sua interpretação, o conceito engloba tudo o que acontece no interior da escola. Os estudos desse autor contribuíram para a compreensão da vida escolar, que pode ser representada através de fatos, mentes, corpos, objetos e modos de pensar. Sua análise se estende por uma visão ampla do conceito, na qual não existe uma cultura escolar, mas existe sim uma variação de acordo com cada instituição investigada. Para 
o autor, a particularidade será a característica produzida pelas instituições educacionais, tais como a análise de fichas individuais que permitem identificar as modificações ao longo do tempo, tais como: mudanças no currículo e métodos de ensino, por exemplo.

Outra perspectiva de análise é utilizada por Farias Filho (2007) que, a partir de objetos escolares, identifica um conjunto de normas que foram incorporadas na vida escolar dos indivíduos. Com isso, cultura escolar

é entendida como a forma em que a situação histórica concreta e particular são articuladas e representadas, pelos sujeitos escolares, as dimensões espaços-temporais do fenômeno educativo escolar, os conhecimentos, as sensibilidades e os valores a serem transmitidos e a materialidade e os métodos escolares (FARIAS FILHO, p. $195)$.

Além disso, observa-se uma crescente valorização da escola e de sua materialidade como fonte de pesquisa e desconstrução da memória educacional. Como assinala Moraes (2002, p. 24),

\begin{abstract}
no redirecionamento atual da pesquisa histórica em educação, enfatiza-se a necessidade de apreender "o que se faz na escola" (CHARTIER, 2000), nos seus diferentes tempos e lugares, atribuindo-se, assim, novo significado às práticas escolares enquanto elementos essenciais constitutivos da realidade educacional e da vida social. Esta perspectiva impõe aos pesquisadores da educação, nos seus mais diversos campos - da história, sociologia, economia, linguística, psicologia e didática - o desafio da preservação das fontes históricas em arquivos públicos e a constituição dos arquivos escolares.
\end{abstract}

Recorreu-se ainda aos estudos sobre o ensino da Educação Física durante o período militar, destacadamente aos trabalhos de Marcus Aurélio Taborda de Oliveira (2002), “Educação Física escolar e ditadura militar no Brasil (1968-1984): história e historiografia", e "Saberes em campo: a configuração do ensino escolar da Educação Física no Estado de São Paulo (1964-1985)", de Jaqueline Costa Castilho Moreira (2013).

A autora Maria João Mogarro (2005) comparece com sua perspectiva direcionada aos arquivos escolares, tratando-os como um repositório de fontes de informações das instituições escolares. A autora propõe uma reflexão sobre o lugar de pertencimento do arquivo, a sua natureza, assim como as suas potencialidades, resultando, por conseguinte, em uma memória educativa.

Vale ressaltar ainda o "Manual de trabalho em arquivos escolares", produção da Maria Aparecida Ceravolo Magnanie Sidnei Sauerbronn (2003), que auxiliou na estruturação da metodologia adotada para o desenvolvimento na pesquisa. Na historiografia conceitual do arquivo, trilhou-se pela obra Correntes atuais do pensamento arquivisticos, do Terry Eastwood e Heather MacNeil (2016), pela legislação arquivística brasileira, por meio de 
questões de temporalidade do arquivo, classificação, preservação e conservação de documentos e pela Norma Brasileira para a Descrição de Documentos Arquivísticos NOBRADE (2006). Também contribuíram para a reflexão acerca da preservação, o trabalho "Preservação do Patrimônio Histórico Escolar no Brasil: notas para um debate", de Rosa Fátima de Souza (2013), e a referência bibliográfica "Educação patrimonial: diálogos entre escola, museu e cidade do Instituto do Patrimônio Histórico e Artístico Nacional - Iphan (2014)".

O presente trabalho se insere na perspectiva de contribuir com a preservação da memória educacional do município de Petrolina. O texto está organizado em duas partes. A primeira trata da origem do ginásio, com ênfase nas práticas culturais, como as festas comemorativas e religiosas. A segunda traça um perfil socioeconômico dos alunos, a partir da análise das fichas de matrículas e antropométricas, bem como discorre acerca da educação profissionalizante, das festas comemorativas e religiosas.

Por fim, a pesquisa aponta para a necessidade de estudos mais aprofundados sobre o papel do ginásio e da Escola Marechal Antônio Alves Filho no Sertão Médio São Francisco, com outros recortes temporais, a fim de ampliar o universo da cultura escolar do sertão pernambucano, contribuindo, dessa forma, com a preservação da memória educacional da região.

\section{DA EDUCAÇ̃̃O HUMANÍSTICA À EDUCAÇÃO TÉCNICA: A SOCIEDADE EM TRANSFORMAÇÃO}

No Brasil, a partir da década de 1930, intensificam-se as discussões sobre o ensino secundário. O aumento da população, o crescimento dos centros urbanos, o desenvolvimento da indústria e dos serviços, tudo conduziu a um aumento generalizado pela demanda por educação (DALLABRIDA; SOUZA, 2014, PESSANHA; BRITO, 2014, SCHWARTZMAN et al. 2009).

Como assinala Souza (2009, p. 87):

Em meados do século $\mathrm{XX}$, as batalhas pelo humanismo na educação brasileira expunham diferentes representações e projetos para a educação secundária. Estava em questão a sobrevivência dos estudos clássicos e a proeminência da cultura científica, mas, sobretudo o destino de uma formação centrada na cultura geral. $\mathrm{O}$ desfecho dessas disputas foi equacionado pela Lei de Diretrizes e Bases da Educação Nacional promulgada em 1961 (Lei 4.024/61). 
Duas reformas foram emblemáticas nesse período. Primeiro, a reforma Francisco Campos de 1931, que alavancou, como afirma Dallabrida (2009), a expansão do ensino secundário no país, como ainda possibilitou a equiparação oficial a todos os estabelecimentos de ensino secundário. A segunda, a Lei Orgânica do Ensino Secundário de 1942, também conhecida como a Reforma Gustavo Capanema, que permaneceu em vigor até 1961. Por essa legislação responsável pela reforma do ensino secundário, ele passou a ser ministrado em dois ciclos: o primeiro compreendeu o curso ginasial, com duração de quatro anos, e o segundo, com dois cursos paralelos: o curso clássico e o curso científico, cada qual com três anos de duração ${ }^{2}$.

No exame de Souza (2008), os principais debates em torno do ensino secundário, entre os anos de 1930 e1960, estiveram em torno das seguintes questões: a expansão do ensino secundário público, que atendesse à crescente demanda, a divisão do ensino secundário em ciclos e a preponderância da formação clássica ou científica.

O caráter humanístico baseado em concepções de cultura geral foi dominante no ensino secundário, até então ${ }^{2}$. Porém, as mudanças no final da década de 1950 e no início de 1960 foram significativas na organização curricular da escola secundária, repercutindo nas práticas educativas e na formação de identidade de cada sujeito. Souza (2008) evidencia que a escola básica - que vai se configurar a partir dos anos 1960 - estaria mais em conformidade com as características do público escolar e da moderna sociedade industrial brasileira.

A primeira LDB (Lei de Diretrizes e Bases, de 1961), aprovada pela Câmara dos Deputados, durante a legislatura 1959-1963, foi marcada por disputas e diferentes interesses, envolvendo diversos grupos políticos e educacionais. De um lado, os liberais escalonovistas que defendiam a escola pública e a concentração do processo educativo pela União e, de outro, os católicos e grupos mais conservadores, que faziam defesa das escolas privadas e pela não interferência do estado.

Essas disputas permaneceram até o golpe militar em 1964. Pode-se dizer que a lei contemplou esses dois grupos por durante treze anos de intensos debates. Na nova organização curricular para o ensino secundário, constavam disciplinas obrigatórias, tais como: Português, Matemática, História, Geografia e Ciências. Além dessa primeira estrutura curricular, existia uma segunda, composta por disciplinas de teor obrigatório, definidas pelos respectivos conselhos estaduais, tais como: “[...] desenho e organização social e política brasileira, ou desenho e uma língua clássica e uma língua estrangeira moderna; ou duas

\footnotetext{
${ }^{2}$ Para maior aprofundamento ver Souza (2008) e Dallabrida (2014).
} 
línguas estrangeiras modernas e filosofia, esta apenas no $2^{\circ}$ ciclo" (TREVIZOLI; VIEIRA; DALLABRIDA, 2013, p. 8). Marchelli (2014) destaca que, com exceção dessas matérias, o estabelecimento de ensino poderia escolher disciplinas optativas, deliberadas pelo Conselho Estadual.

No ciclo ginasial, eram ministradas as disciplinas de línguas estrangeiras modernas, música (canto orfeônico), artes industriais, técnicas comerciais e técnicas agrícolas, enquanto no colegial eram oferecidas as de línguas estrangeiras modernas, grego, desenho, mineralogia e geologia, estudos sociais, psicologia, lógica, literatura, introdução às artes, direito visual, elementos de economia, noções de contabilidade, biblioteconomia, puericultura, higiene e dietética (SOUZA, 2008).

Na percepção de Souza (2008), a nova estrutura curricular do ensino secundário se voltou para a valorização de aprendizagens ligadas aos conhecimentos gerais e técnicos, de forma a almejar objetivos de preparação profissional, que não eram centrados exclusivamente na concepção de formação humanista das escolas do passado.

A LDB/1961 foi uma lei que teve movimentos de rupturas e continuidades. Entre as mudanças, destaca-se a democratização do ensino secundário, principalmente para a classe popular. A ideia subjacente era proporcionar uma escolarização da massa para a formação de mão-de-obra qualificada para o trabalho industrial, visto que o país estava vivendo um período de crescimento, aceleração da industrialização e urbanização, em consonância com a cultura técnico-científica, proposta resgatada na reforma Francisco Campos, em 1942 (DALLABRIDA; SOUZA 2014). A análise do Art. $1^{\circ}$ da lei evidencia a definição de novos objetivos para a educação:

Art. $1^{\circ}$ - A educação nacional, inspirada nos princípios de liberdade e nos ideais de solidariedade humana, tem por fim:

\begin{abstract}
a) a compreensão dos direitos e deveres da pessoa humana, do cidadão, do Estado, da família e dos demais grupos que compõem a comunidade; b) o respeito à dignidade e às liberdades fundamentais do homem; $\mathrm{c}$ ) o fortalecimento da unidade nacional e da solidariedade internacional; d) o desenvolvimento integral da personalidade humana e a sua participação na obra do bem comum; e) o preparo do indivíduo e da sociedade para o domínio dos recursos científicos e tecnológicos que lhes permitam utilizar as possibilidades e vencer as dificuldades do meio e a preservação e expansão do patrimônio cultural [...] (BRASIL, 1961).
\end{abstract}

Segundo Marchelli (2014), a escola continuou a ser restrita e excludente, mas, no âmbito da ideologia de progresso e prosperidade dominante, ela se uniria à fábrica para ajudar na realização do projeto político dos governos populistas que se sucederam de 1930 a 1964 . 
Nessas reformas educacionais, tiveram predominância os interesses das minorias responsáveis pelo golpe militar de 1964 e da burguesia internacional, a partir dos acordos MEC-USAID entre Brasil e Estados Unidos. O argumento defendido nesse acordo era a necessidade de integração das escolas de ensino primário e médio, de forma que se estendesse à escolaridade, eliminando a compartimentação da escola elementar e da escola média, ou seja, pressupunha um tipo de integração em que o primeiro ciclo da escola média ficasse mais ligado à escola primária.

De fato, o marco principal da reforma da educação brasileira, no que se refere ao ensino fundamental e médio, neste período, foi a promulgação a Lei $n^{0} 5.692$, de 11 de agosto de 1971. Essa lei concebe um dos mais significativos momentos da reforma do ensino de $1^{\circ} \mathrm{e}$ $2^{\circ}$ graus, e se insere dentro de um regime político de exceção durante o Governo Médici. Esse período é conhecido como "Milagre econômico" (ASSIS, 2012).

\section{O GINÁSIO E A CIDADE: EDUCAÇÃO PROFISSIONALIZANTE, FESTAS COMEMORATIVAS E RELIGIOSAS}

Em Petrolina, cidade situada no sertão pernambucano, a criação do primeiro ginásio partiu da iniciativa do prefeito Luís Augusto Fernandes, durante o seu mandato entre os anos de 1959 e 1963. Dr. Augusto, como era conhecido, também foi responsável pela criação da Fundação Educacional de Petrolina - FEP ${ }^{3}$, em 1961. A solenidade de lançamento da pedra fundamental, daquele que seria o Ginásio Industrial de Petrolina (GIP), ocorreu em janeiro de 1962. O evento contou com a presença de autoridades, moradores locais e de regiões circunvizinhas.

Aguardada com entusiasmo, a autorização de funcionamento do ginásio, por parte da Inspetoria Seccional do Ensino Secundário do Estado de Pernambuco, foi noticiada no jornal O Pharol, impresso de maior circulação da cidade. O jornal ressaltava ainda o papel da Fundação Educacional de Petrolina no desenvolvimento da cidade com a abertura do ginásio. O GIP iniciou suas atividades temporariamente, provavelmente em março de $1963^{4}$, no prédio

\footnotetext{
3 A Fundação Nilo Coelho é uma organização social que, desde 1961, trabalha para que os direitos de crianças, adolescentes, mulheres, deficientes físicos, mentais e idosos sejam respeitados. O estágio que a organização alcançou permitiu que a partir de 2010, firmasse parceria com o Governo Federal, através da CHESF (Companhia Hidroelétrica do São Francisco), Governo de Pernambuco, através da Secretaria da Mulher e FUNDARPE (Fundação do Patrimônio Histórico e Artístico de Pernambuco). Informações disponíveis em: http://fundacaonilocoelho.org.br/sobre-nos. Acesso: 20 nov. 2017.

${ }^{4}$ Não foram localizadas informações acerca da data de início das atividades do ginásio.
} 


\section{$(\mathrm{cc}) \mathrm{EY}$}

do antigo Grupo Escolar D. Malan ${ }^{5}$, criado em 1950. O ginásio nasceu voltado à educação profissionalizante. A publicação com a autorização de funcionamento no Diário Oficial do Estado, no entanto, somente ocorreria três mais tarde, em 06 de maio de 1965

A primeira turma do GIP contou com 50 alunos. À época foram oferecidos cursos de aprendiz profissionalizante nas áreas de tecelagem, monotécnico, eletricidade, marcenaria, artes gráficas, corte e costura, culinária, confecção de flores, bordados e pintura.

Figura 1: Primeira turma de ensino profissionalizante do GIP, em 1964.

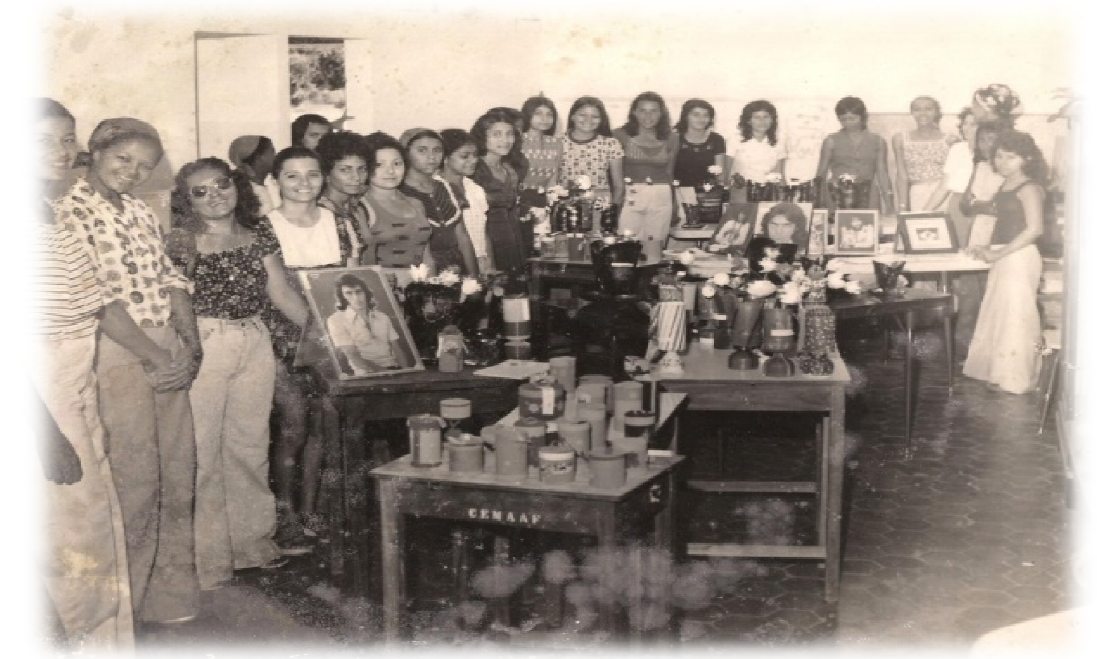

Fonte: Acervo E.M.A.A.F., 2016.

Figura 2: Turma do curso de tecelagem no GIP, em 1965.

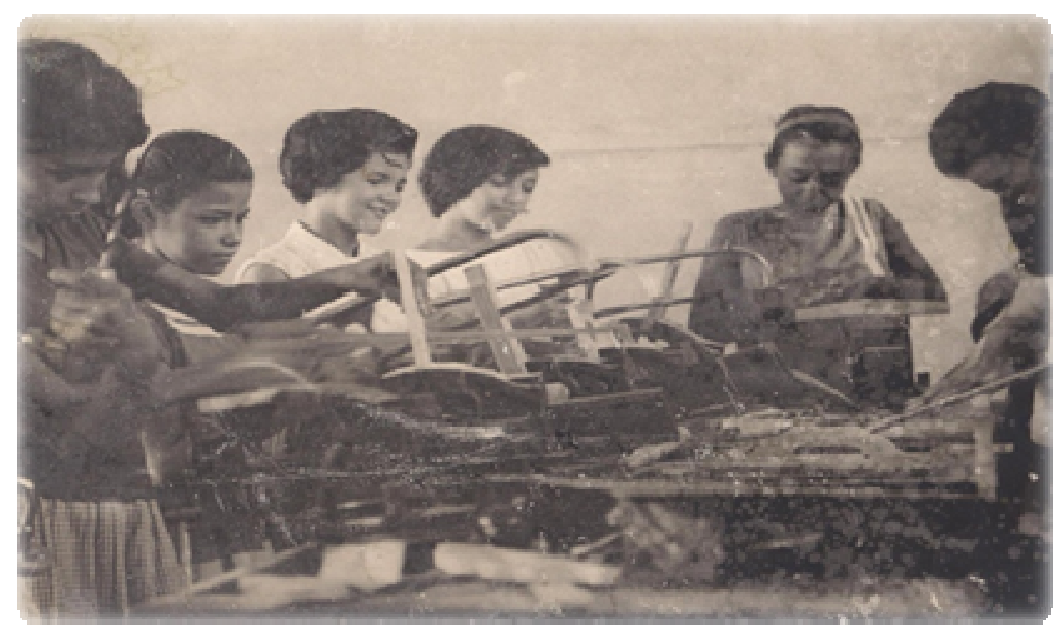

Fonte: Acervo E.M.A.A.F., 2016.

Em 1971, com a reforma do ensino (Lei n. 5.692), o Ginásio Industrial de Petrolina passou a pertencer à Rede Estadual de Ensino e sua nomenclatura foi modificada para Colégio

\footnotetext{
${ }^{5}$ Sobre o Grupo Escolar Dom Malan, ver o estudo de Ávila (2016).
} 


\section{$(\mathrm{cc}) \mathrm{EY}$}

Estadual de $2^{\circ}$ Grau Marechal Antônio Alves Filho - CEMAAF, sendo oferecido inicialmente o $1^{\mathrm{o}}$ ano Científico. O nome da escola foi escolhido em homenagem ao Marechal Antônio Alves Filho, natural do estado do Piaú, primeiro piauiense a conseguir brevê de piloto, documento que dá ao seu titular a permissão para pilotar aviões (Brevet ou Brevê), que fixou residência em Petrolina e se casou com Dulcinéa de Souza Coelho, filha de Clementino de Souza Coelho.

A primeira diretora da GIP, professora Mary de Sousa Barros, era natural de Paulista, interior do estado do Piauí, mas residia em Petrolina desde a infância. Faleceu em 4 de outubro de 2016 aos 93 anos de idade. Popularmente conhecida como Mary Belgium, formou-se no Magistério, com especialização no curso intensivo de Pré-Orientação Profissional, em Recife. De acordo com relatos de professores e alunos que frequentaram a escola nesse período, ela foi uma figura importante para a educação no município, especialmente quando esteve à frente da direção da E.M.A.A.F., permanecendo no cargo de 1965 a 1989, período marcado pela Ditadura Militar.

Figura 4: Professora Mary Belgium, em 2015.

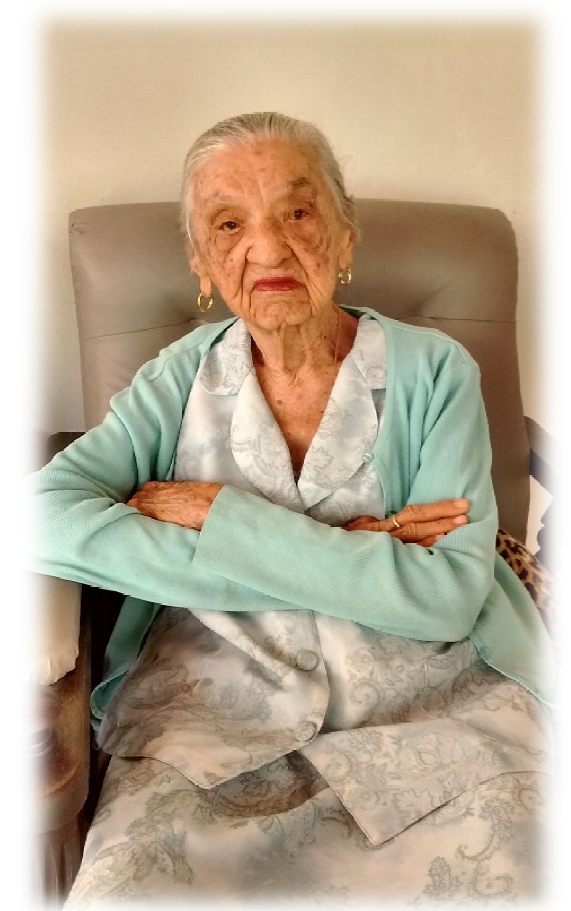

Fonte: Acervo Grupo de Estudos e Pesquisas em História da Educação - GEPHESF.

$\mathrm{Na}$ direção da escola, a professora Mary Belgium mantinha uma conduta disciplinadora baseada no altruísmo e na fé, revelando, assim, um caráter conservador e de base religiosa. Aliás, uma das preocupações da professora era com a formação religiosa. 
Nesta direção, ela procurava desenvolver as atividades escolares. Dentre algumas, destaca-se a realização das cerimônias da primeira comunhão para os alunos da escola.

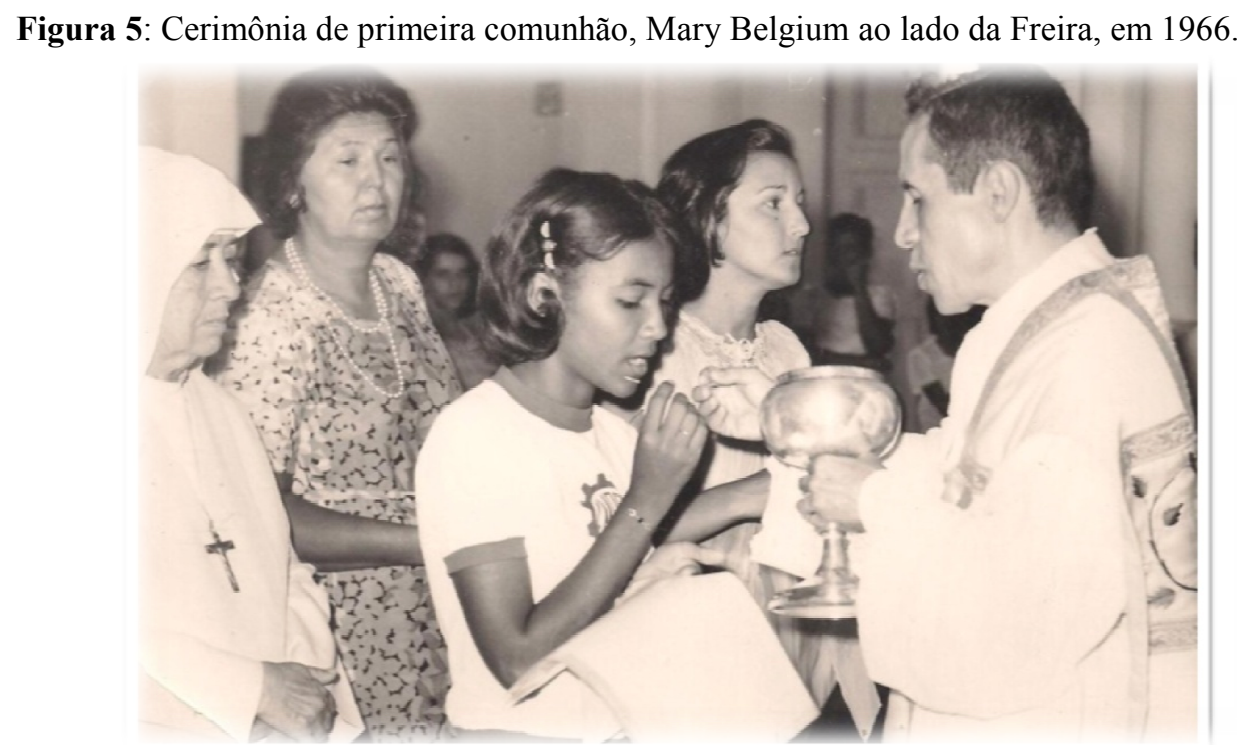

Fonte: Acervo E.M.A.A.F., 2016.

O GIP se notabilizou em Petrolina também pela realização de atividades de cunho artístico e cultural. Dentre elas, a Banda Marcial, o grupo de teatro e o grupo de dança do coco. A Banda foi criada em 1969, pela Professora Mary Belgium, por meio de uma doação do Prefeito de Petrolina, José de Sousa Coelho. A proposta da banda era melhorar o nível das festas escolares no município. Podemos inferir que as festas escolares expressam um aspecto da cultura escolar, porque ao mesmo tempo em que são regidas por normas, ensinamentos de condutas, são também compostas de práticas com finalidades educativas. Nesse período, as festas escolares/cívicas foram utilizadas como instrumento do Estado para a regulação da ordem política e da submissão às regras.

De acordo com Carvalho (1989), as datas festivas auxiliariam os alunos a internalizar valores considerados importantes, entre os quais, a desenvoltura em expressar-se em público, o disciplinamento do cotidiano escolar, o convívio dentro de códigos sociais vigentes. A permanência de datas festivas no calendário escolar indica na concepção de Gallego (2003 apud ÁVILA, 2013) uma forma de regular o que deveria ser lembrado. Para Ávila (2013), o culto aos principais símbolos do cristianismo, a ênfase nos heróis e nos santos permanece nos feriados do calendário das escolas públicas até os dias atuais.

Nesse aspecto, a igreja Católica tem um papel importante, quer na promoção das festas religiosas como das festas cívicas. Com GIP, essa realidade não foi diferente. À frente da 
direção da escola por 24 anos, a professora Mary Belgium irá refletir esse pilar importante que foi o culto ao cristianismo nas escolas, com forte presença na região, até os dias atuais.

\section{DAS FICHAS DE MATRÍCULA ÀS FICHAS ANTROPOMÉTRICAS: APONTAMENTOS SOBRE O PERFIL DE ALUNOS}

Com relação ao perfil dos alunos (as) que frequentaram o GIP, entre os anos de 1962 e 1971, toma-se como base alguns vestígios da cultura escolar presentes nas fichas de matrícula e fichas antropométricas, considerando os aspectos relativos ao sexo, idade, naturalidade, filiação, peso, altura, bem como os dados concernentes às festas e às atividades culturais. Para Silva (2011), as fichas da vida escolar do alunado são documentos produzidos pelos estabelecimentos escolares para registrar dados relevantes ao colégio sobre os discentes. Geralmente, são estruturados de forma padronizada pela própria instituição de ensino, ou por órgão responsável, a serem preenchidos por cada escola. Essas fichas acompanham outros dados importantes sobre os alunos, como: vacinação, atestados de saúde, requerimentos de matrículas, advertências de professores, solicitações de transferências entre outros dados sobre cada aluno.

Para a História da Educação, esses documentos podem ser materiais valiosíssimos, principalmente para a história de instituição escolar. Como relata Silva $(2011$, p. 8):

\footnotetext{
As fichas e a documentação que as acompanham têm como finalidade além de reunir toda informação e dado dos discentes separadamente, servir, posteriormente, para elaboração de documentos escolares, como: históricos escolares, declarações, entre outros. Também são úteis para relevantes informações estatísticas, considerando que no momento, meados do século XX, os avanços tecnológicos e a informatização ainda não compunham o cenário educacional de catalogação de dados.
}

A partir da ficha individual do aluno, ainda é possível refletir sobre o funcionamento da escola, organização do currículo escolar, instrumentos de avaliação, tais como: exercícios, provas (orais e escritas) (SILVA, 2011). 
Figura 6: Ficha Individual - Notas, em 1969.

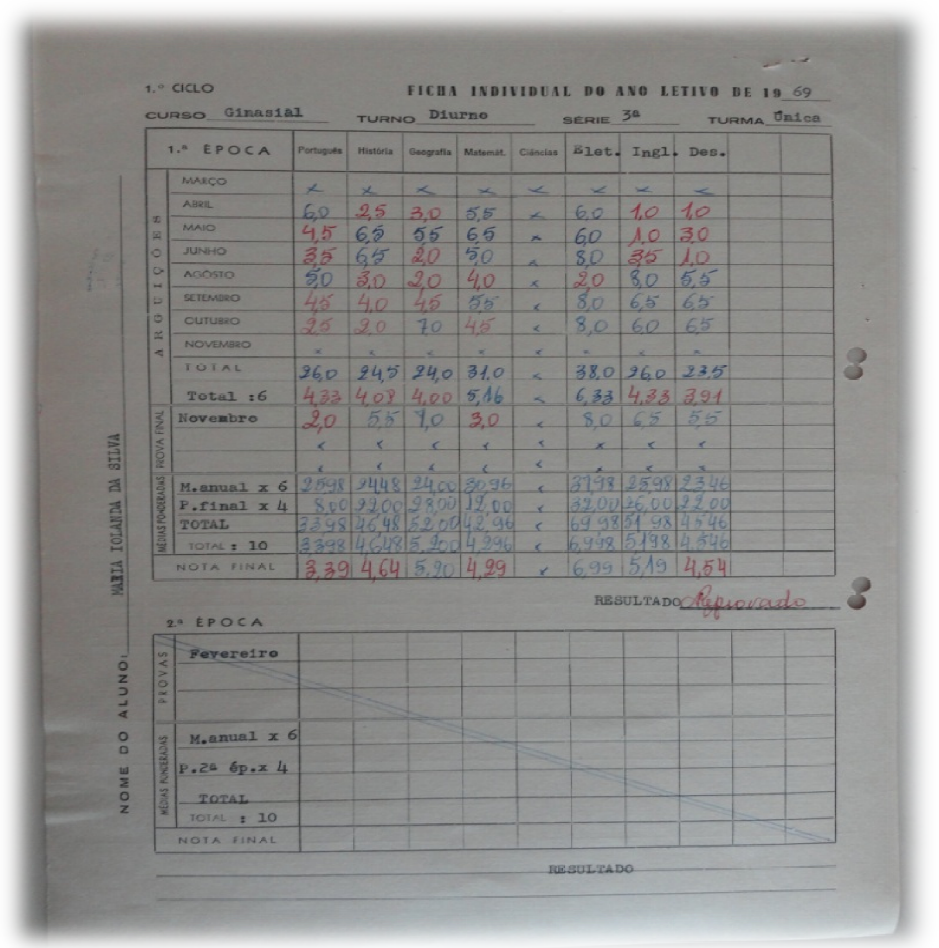

Fonte: Acervo E.M.A.A.F., 2016.

Figura 7: Frente e verso da ficha individual do Ginásio Industrial de Petrolina, em 1968.
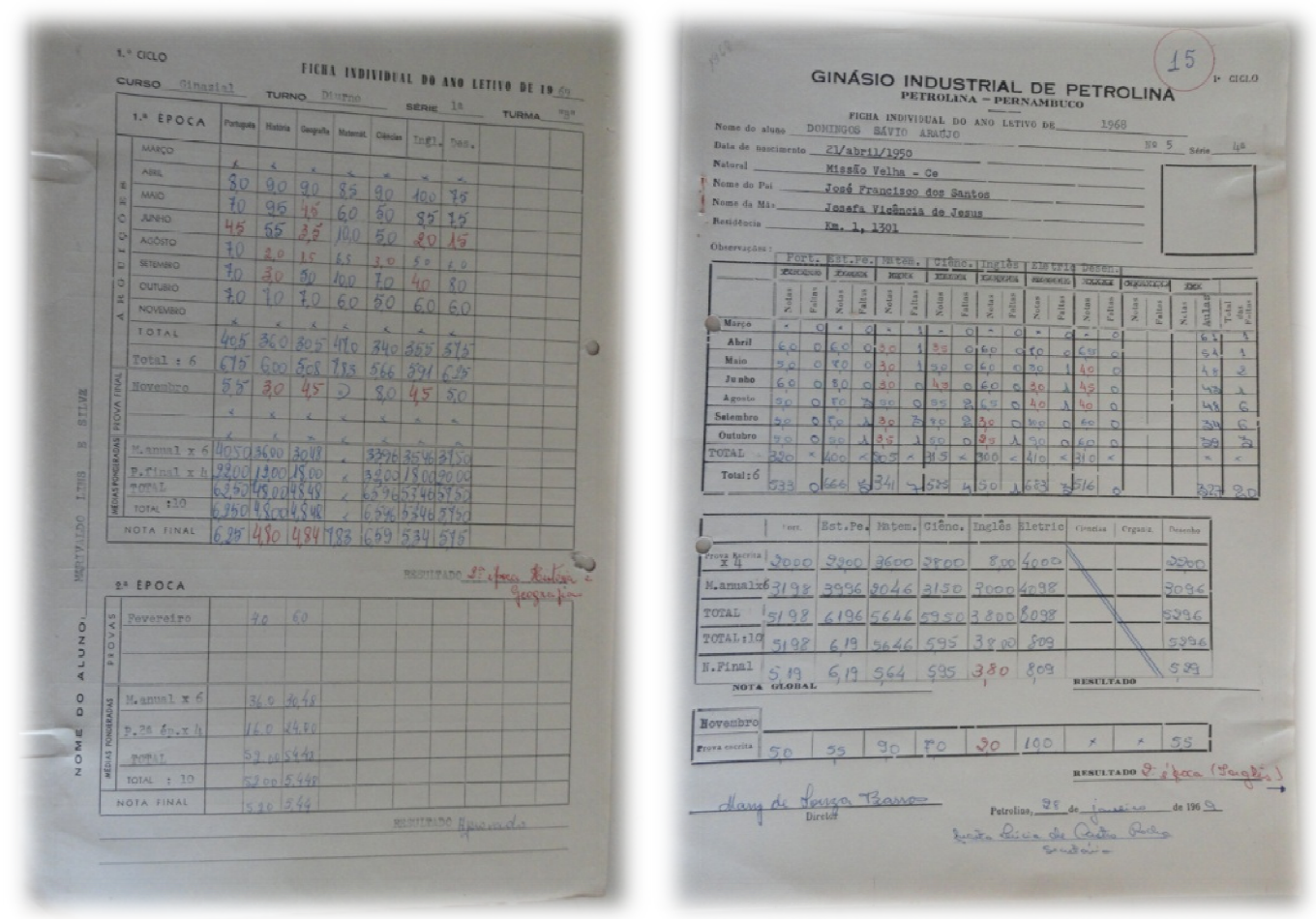

Fonte: Acervo E.M.A.A.F., 2016.

O resultado do levantamento de informações sobre a vida escolar dos(as) alunos(as) foi realizado particularmente com base na ficha individual, a partir de dados pessoais específicos, 
como o quantitativo de meninas e meninos, e a cidade de origem. A delimitação temporal abarcou os anos de 1962-1971. Ao total, foram localizadas 104 fichas.

Gráfico 1: Naturalidade dos(as) Alunos(as), 1962-1971.

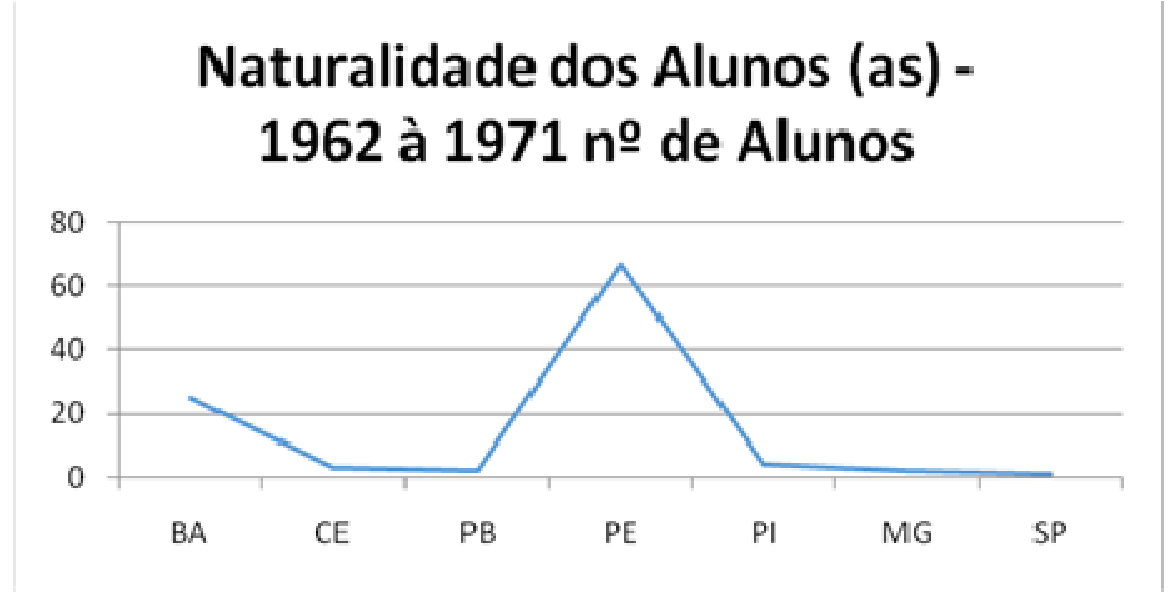

Fonte: Acervo E.M.A.A.F., 2016.

Em relação ao gráfico 1, destinado a análise da origem dos alunos, observa-se um número expressivo de estudantes que migraram de cidades circunvizinhas, como serão os casos de Santa Maria da Boa Vista, Salgueiro e Orocó, no estado de Pernambuco. O Estado da Bahia é o segundo, com algumas cidades distantes de Petrolina. Nesse estado, a predominância é de municípios que fazem fronteira com Petrolina, como Casa Nova, Sobradinho e Curaçá.

A migração pode ser compreendida por dois fatores. O primeiro está relacionado ao acelerado processo de industrialização nesse período. O segundo fator pode estar relacionado à formação profissionalizante ofertada pelo GIP e à disponibilização de mão de obra para o mercado de trabalho, como se observa no art. $1^{\circ}$ da Lei 5.692/71 quando diz:

$\mathrm{O}$ ensino de $1^{\circ}$ e $2^{\circ}$ graus tem por objetivo geral proporcionar ao educando a formação necessária ao desenvolvimento de suas potencialidades, como elemento de auto-realização, qualificação para o trabalho e preparo para o exercício consciente da cidadania (BRASIL, 1971). 
Gráfico 2: Quantitativo por sexo (1962-1971).

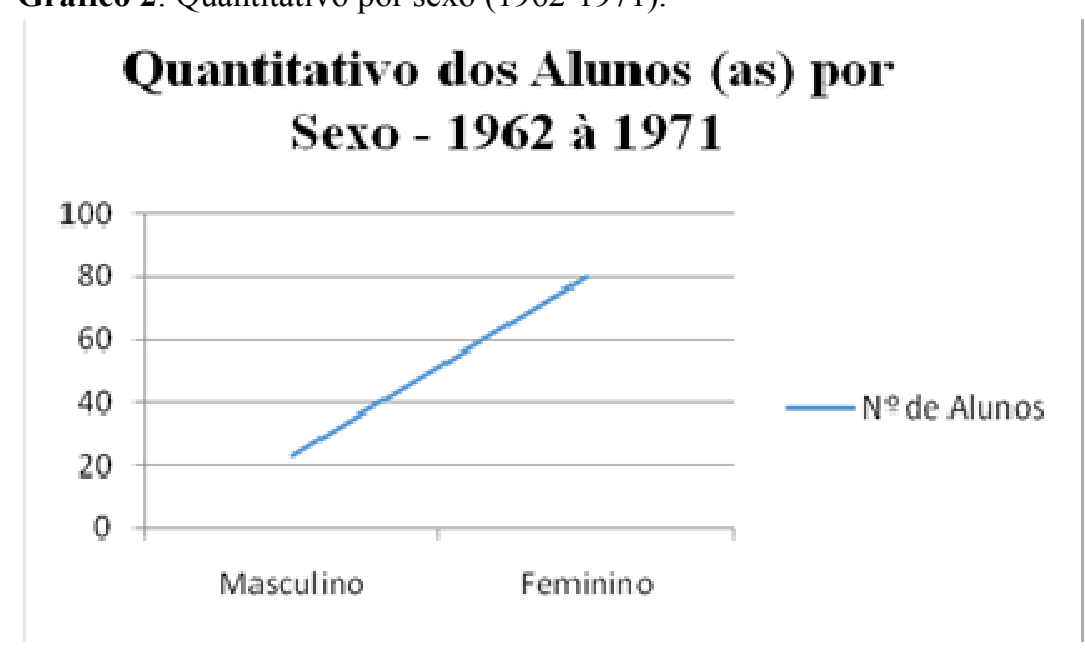

Fonte: Acervo E.M.A.A.F., 2016.

Com relação ao sexo, o expressivo número de meninas que frequentaram o GIP é indicativo de atenção. $\mathrm{O}$ aumento no número de alunos do sexo masculino sofrerá uma mudança no início da década de 1970, quando apresenta um pequeno aumento no número de matrículas. Em relação às fichas biométricas, essas faziam parte dos arquivos dos médicos escolares e, normalmente, não ficavam armazenadas nos acervos das escolas. Embora fosse parte dos documentos pessoais dos alunos, somente eram requeridas aos médicos e disponibilizadas aos discentes, para efetivação de sua matrícula ou em caso de transferência para outra unidade. Esse procedimento era realizado por toda rede educacional pública brasileira (MOREIRA, 2003).

Figura 7: Ficha Biométrica, entre 1965-1967.

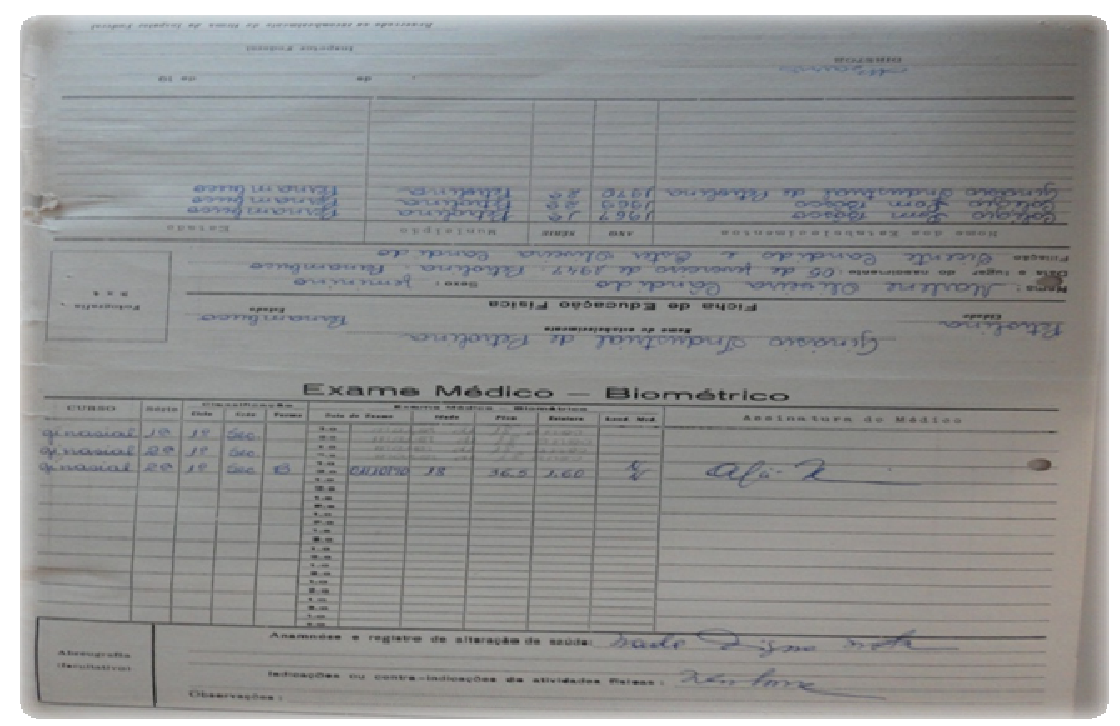

Fonte: Acervo E.M.A.A.F., 2016. 
$\mathrm{Na}$ ficha biométrica, constavam dados sobre o peso, a altura, a idade, as observações sobre alterações de saúde, as indicações ou as contraindicações físicas e o laudo médico que atestava o estado do aluno(a), como se encontrava em normalidade ou não.

Outro aspecto a ser ressaltado se refere aos jogos estudantis e universitários brasileiros, que em nenhuma outra época receberam tantos incentivos como no período militar. No GIP, por exemplo, o time de handebol era imbatível, pois, foram 22 títulos. No calendário das festividades de Petrolina, os jogos escolares ocupavam lugar de destaque. Vale lembrar que a primeira Lei de Diretrizes e Bases da Educação Nacional (LDB), Lei n 4024/618 de 1961, tornou obrigatória, em seu art. 229, a Educação Física no ensino primário e médio.

Em 1969, o Decreto-Lei no 705 , de 25 de julho de 1969, alterou a redação do artigo $22^{\circ}$ da LDB n 4.024/1961, que passou a vigorar da seguinte maneira: "Será obrigatória a prática da educação física em todos os níveis e ramos de escolarização, com predominância esportiva no ensino superior" (BRASIL, 1969a, p. 8). No mesmo ano, o Decreto-Lei $n^{\circ} .865$, de 12 de setembro de 1969 (BRASIL, 1969b), reafirmou a obrigatoriedade da inclusão da Educação Física (e também da Educação Moral e Cívica, da Educação Artística e dos Programas de Saúde) nos currículos plenos dos estabelecimentos de $1^{\circ}$ e $2^{\circ}$ graus.

No exame de Moreira (2013), no período compreendido entre 1964-1985, houve uma confluência de elementos relevantes para a escolarização da Educação Física, entre os quais a obrigatoriedade; um maior incentivo à atuação dos órgãos de fiscalização, no caso a Divisão de Educação Física (DEF) e o Departamento de Educação Física e Esportes paulista (DEFE); a expansão do ensino; o desenvolvimento de pesquisa e do campo acadêmico, acompanhando o foco mundial nos desportos; o registro da práxis transformando-o em conhecimento formal e a ressignificação e reinvenção do cotidiano escolar pelos sujeitos educacionais, frente a todas essas vicissitudes.

Nessa direção, para Taborda de Oliveira (apud MOREIRA, 2013), questões-chave como a opção pelo desenvolvimento do país e a expansão da Educação precisariam ser revistas. Como ele mesmo diz, um regime que pretendia ampliar e consolidar seu domínio, mesmo que pelo viés tecnocrático, tinha que assumir uma postura de desenvolvimento em perspectiva nacional e internacional. Daí a Educação ser um dos seus principais enfoques.

\section{CONSIDERAÇÕES INICIAIS}

O trabalho de investigação histórica dentro de arquivos é instigante. Nesse primeiro contato com os documentos do primeiro ginásio de Petrolina, foi possível captar vestígios da 
cultura escolar presentes nas festas, nas comemorações e nos jogos escolares, bem como nas fichas individuais e antropométricas dos alunos.

$\mathrm{Na}$ ficha biométrica, constavam dados sobre o peso, a altura, a idade, observações sobre alterações de saúde, indicações ou contraindicações físicas e o laudo médico que atestava o estado do aluno (a), como se encontrava em normalidade ou não.

O ginásio também se notabilizou em Petrolina pela realização de atividades de cunho artístico e cultural. Dentre elas, a Banda Marcial do GIP, o grupo de teatro e o grupo de dança do coco. A banda foi criada em 1969, pela Professora Mary Belgium, por meio de uma doação do Prefeito de Petrolina, José de Sousa Coelho. A proposta da banda era melhorar o nível das festas escolares no município.

Nesse período, as festas escolares/cívicas foram utilizadas também como instrumento do Estado para a regulação da ordem política e da observância às regras. Os jogos estudantis e universitários brasileiros, em nenhuma outra época receberam tantos incentivos como no período militar. No GIP, por exemplo, o time de handebol era imbatível, foram 22 títulos. No calendário das festividades de Petrolina, os jogos escolares ocupavam lugar de destaque, proporcionando à população local a ampliação das redes de sociabilidade e da vida comunitária.

Como se observa, a temática é envolvente e necessita de investigações mais aprofundadas com outros recortes temporais a fim de se ampliar o universo da cultura escolar do sertão pernambucano, contribuindo, dessa forma, com a preservação da memória educacional da região.

\section{REFERÊNCIAS}

ÁVILA, Virgínia P. S. A escola no tempo: a construção do tempo em escolas isoladas (Florianópolis - 1930-1940). Florianópolis: UDESC, 2013.

. Entre mangueiras e coqueiros: Grupo escolar Dom Malan e a política nacional de educação rural (1949-1953). In: LIMA, Sandra Cristina Fagundes de; MUSIAL, Gilvanice Barbosa da Silva. Histórias e memórias da escolarização das populações: Sujeitos, Instituições, Práticas, Fontes e Conflitos. Jundiaí: Paco Editorial, 2016.

ASSIS, Renata. A educação brasileira durante o período militar: a escolarização dos 7 aos 14 anos. Educação em Perspectiva, v. 3, n. 2, p. 320-329, jul./dez, 2012.

BRASIL. Lei $\mathbf{n}^{0}$ 4.024, de 20 de dezembro de 1961. Fixa as diretrizes e bases da educação nacional. Lei de Diretrizes e Bases da Educação-LDB. Brasília, DF, 1961. Disponível em: 
$<$ http://www2.camara.leg.br/legin/fed/lei/1960-1969/lei-4024-20-dezembro-1961-353722norma-pl.html>. Acesso: 15 nov. 2017.

. Decreto-Lei $\mathbf{n}^{0} 705$ de 25 de julho de 1969. Altera a redação do artigo 22 da Lei ${ }^{\circ}$ $\overline{4.024}$ de 20 de dezembro de 1961. 1969a. Disponível em: http://www.planalto.gov.br/ccivil_03/decreto-lei/1965-1988/Del0705.htm. Acesso: 16 nov. 2017.

. Decreto-lei $n^{\circ} 865$, de 12 de setembro de 1969. Declara de interesse da Segurança Nacional, nos têrmos do art. $16, \S 1^{\circ}$, alínea $\mathrm{b}$, da Constituição, o Município que especifica, e dá outras providências. 1969b. Disponível em:<http://www.planalto.gov.br/ccivil_03/Decreto-Lei/1965-1988/Del0865.htm>. Acesso em: 14 nov. 2017.

Lei $n^{\circ}$ 5.692, de 11 de agosto de 1971. Fixa diretrizes e bases para o ensino de $1^{\circ}$ e

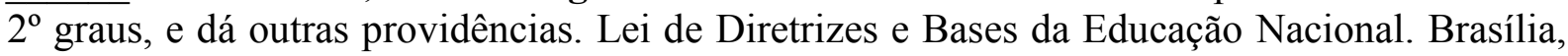
DF, 1971. Disponível em: <http://www2.camara.leg.br/legin/fed/lei/1970-1979/lei-5692-11agosto-1971-357752-publicacaooriginal-1-pl.html>. Acesso em: 14 nov. 2017.

Conselho Nacional de Arquivos. NOBRADE: Norma Brasileira de Descrição Arquivística. Rio de Janeiro: Arquivo Nacional, 2006. Disponível em: $<$ http://www.conarq.arquivonacional.gov.br/images/publicacoes_textos/nobrade.pdf $>$ Aces so em: 15 nov. 2017.

BURKE, Peter. A Escola dos Annales (1929-1989): a Revolução Francesa da Historiografia. São Paulo: Fundação Editora da UNESP, 1997.

DALLABRIDA, Norberto. A reforma Francisco Campos e a modernização nacionalizada do ensino secundário. Educação, Porto Alegre, v. 32, n. 2, p. 185-191, maio/ago. 2009.

; SOUZA, Rosa Fátima. (Orgs.). Entre o ginásio de elite e o colégio popular: estudos sobre o ensino secundário no Brasil (1931-1961). Uberlândia: EDUFU, 2014.

OLIVEIRA, Marcos A. T. de. Educação Física escolar e ditadura militar no Brasil (19681984): história e historiografia. Educação e Pesquisa, São Paulo, v. 28, n. I, p. 51-75, jan./jun. 2002.

ESTWOOD, Terry; MACNEIL, Heather. (Orgs.). Correntes atuais do pensamento Horizonte: arquivistico. Tradução de Anderson Bastos Martins. Revisão técnica Heloísa Liberalli. Belo Horizonte: Editora UFMG, 2016.

FARIA FILHO, Luciano Mendes. Escolarização e Cultura Escolar no Brasil: reflexões em torno de alguns pressupostos e desafios. In: BENCOSTA, Marcus Levy Albino. (Org.). Cultura Escolares, Saberes e Práticas Educativas. Itinerário Histórico. São Paulo: Cortez, 2007.

GOMES, João. O PHAROL. Petrolina, 31 de janeiro de 1962, p. 1, n. 9.

MARCHELLI, Paulo Sérgio. Da LDB 4.024/61 ao debate contemporâneo sobre as bases curriculares nacionais. Revista Científica e-Curriculum, São Paulo, v. 12, n. 3, p. 1480- 
$<$ https://revistas.pucsp.br/index.php/curriculum/article/view/21665> Acesso: 04 out. 2015.

SECRETARIA DE EDUCAÇÃO. Manual de trabalho em arquivos escolares. Elaboração de Teresa Marcela Meza Baeza. São Paulo: CRE Mário Covas, IMESP, 2003.

MOGARRO, Maria João. Arquivo e Educação. A construção da memória educativa. Sísifo, Revista de Ciências da Educação, 1, pp. 71-84, 2006.

MORAES, Carmem Sylvia Vidigal; ALVES, Júlia Falivene. Inventário de fontes documentais. São Paulo: Imprensa Oficial, 2002.

MOREIRA, Jaqueline Costa Castilho. Saberes em campo: a configuração do ensino escolar da Educação Física no Estado de São Paulo (1964-1985). 2013. 321 f. Tese (Doutorado em Educação) - Universidade Estadual Paulista “Júlio de Mesquita Filho", Faculdade de Ciências e Letras de Araraquara. Disponível em: <http://hdl.handle.net/11449/101549>.

PESSANHA, Eurize Caldas; BRITO, Silvia Helena Andrade. Ensino secundário ou educação secundária? Controvérsias e singularidades na escrita de sua história. Série-Estudos Periódico do Programa de Pós-Graduação em Educação da UCDB, [S.1.], p. 237-250, nov. 2014. Disponível em: <http://www.serie-estudos.ucdb.br/index.php/serieestudos/article/view/750/65>. Acesso: 30 set. 2017.

QUINTANA, Mario. Sapato florido. Porto Alegre: Globo, 1948.

NASCIMENTO, Maria Isabel Moura; SANDANO, Wilson; LOMBARDI, José Claudinei; SAVIANI, Dermeval. (Orgs.) Instituições Escolares no Brasil: Conceito e reconstrução histórica. Campinas: Autores Associados, 2007.

SILVA, Viviane de Melo. Ficha da Vida Escolar do Alunado como Fonte para a História de Instituições Escolares: Uma discussão. In: CONGRESSO BRASILEIRO DE HISTÓRIA DA EDUCAÇÃO, 7, 2013, Anais... Cuiabá, MT: SBHE, 2013.

SOUZA, Rosa Fátima de. Preservação do patrimônio escolar no Brasil: notas para um debate. Revista Linhas, Florianópolis, v. 14, n. 26, jan/jun. 2013, p. 199-221.

História da organização do trabalho escolar e do currículo no Século XX: ensino primário e secundário no Brasil. São Paulo: Cortez, 2008.

A Renovação do Currículo do Ensino Secundário no Brasil: as últimas batalhas pelo humanismo (1920-1960). Currículo sem Fronteiras, v. 9, n. 1, p. 72-90, Jan/Jun 2009.

SCHWARTZMAN, Simon; BOMENY, Helena Maria Bousquet; COSTA, Vanda Maria Ribeiro. Tempos de Capanema. 2. ed. Rio de Janeiro: Paz e Terra, 2000. Disponível em: $<$ http://www.schwartzman.org.br/simon/capanema/introduc.htm>. Acesso em: 12 nov. 2009.

TREVIZOLI, Dayane Mezuran; VIEIRA, Letícia; DALLABRIDA, Norberto. As mudanças experimentadas pela cultura escolar no ensino secundário devido à implementação da Reforma Capanema de 1942 e da Lei de Diretrizes e Bases da Educação de 1961. Colóquio Ensino Médio, história e cidadania, v. 3, n. 3, 2013, p.1-13. 
VIÑAO FRAGO, A. Historia de la educación e historia cultural. Revista brasileira de Educação, São Paulo, n. 0, p. 63-82, set/dez, 1995.

Recebido em: 24 de novembro de 2017 Aceito em: 15 de dezembro de 2017 